\title{
Density and Viscosity Correlations for Aqueous 3-Amino-1- propanol and Monoethanol Amine Mixtures
}

\author{
Sumudu S. Karunarathne Lars E. Øi \\ Faculty of Technology, Natural Sciences and Maritime Sciences, University of South-Eastern Norway, Norway, \\ \{Sumudu. karunarathne, lars.oi\}@usn.no
}

\begin{abstract}
Density and viscosity data and relevant correlations are essentially needed to perform mathematical modelling and simulations for the design of process equipment. Correlations that are developed to cover a range of concentrations and temperatures help to use them in mathematical modelling and simulations of absorption desorption processes. In this study, a density correlation was proposed for 3A1P (3-Amino-1-propanol) $+\mathrm{H}_{2} \mathrm{O}$ mixtures. The McAllister three body model was adopted to correlate kinematic viscosity data of MEA (monoethanol amine) $+\mathrm{H}_{2} \mathrm{O}$ mixtures and kinematic viscosity data for $3 \mathrm{~A} 1 \mathrm{P}+\mathrm{H}_{2} \mathrm{O}$ mixtures. The Eyring's viscosity model based on absolute rate theory was used to correlate dynamic viscosity data. A Redlich - Kister type polynomial was proposed to fit the excess free energy of activation for viscous flow for $3 \mathrm{~A} 1 \mathrm{P}+\mathrm{H}_{2} \mathrm{O}$ mixtures. The developed correlations were able to represent density and viscosity data with accepted accuracy and can be used to perform engineering calculations.
\end{abstract}

Keywords: density, viscosity, MEA, 3A1P, McAllister model

\section{Introduction}

Acid gas removal using aqueous alkanolamines through chemical absorption has been in practice for decades to remove $\mathrm{CO}_{2}$ from natural gas (Eimer, 2014; Rochelle, 2009). The integration of this technology to a commercial level in Post-Combustion $\mathrm{CO}_{2}$ Capture is halted by economic feasibility due to the energy demand of the process. High reaction rate with $\mathrm{CO}_{2}$ and low regeneration energy in stripping are ideal characteristics for an absorbent to reduce the cost of operation.

Physical properties like density, viscosity and surface tension are essential in various aspects such as designing/sizing of process equipment and process simulations. They appear in many mass and heat transfer correlations that are essential in the mathematical modelling transport process and design of the absorption column. Empirical correlations of such properties can provide the required data within a considered concentration and temperature range. Abundant resources are available for the density and viscosity of aqueous MEA (monoethanol amine) in the literature with suggested correlations, while reported studies are limited for 3A1P (3-Amino-1-propanol) (Idris and Eimer, 2016; Idris et al., 2018).

\section{Density and Viscosity Correlations for Binary Mixtures}

Correlations based on excess volume $V^{E}$ are commonly adopted to fit density data of liquid mixtures and the Redlich-Kister (Redlich and Kister, 1948) type polynomial is suggested to correlate $V^{E}$. This approach requires a higher number of parameters to correlate $V^{E}$ to acquire high accuracy of data fit (Aronu et al., 2012). Such studies are reported for densities of aqueous MEA and 3A1P solutions under different compositions and temperatures in the literature (Han et al., 2012; Idris and Eimer, 2016).

$$
\begin{aligned}
& V^{E}=V-\sum_{i=1}^{n} x_{i} V_{i}^{o} \\
& \rho=\frac{\sum_{i=1}^{n} x_{i} \cdot M_{i}}{V^{E}+\sum_{i=1}^{n} \frac{x_{i} \cdot M_{i}}{\rho_{i}}}
\end{aligned}
$$

McAllister, (1960) viscosity model presents a theoretical approach based on molecular attractions arises from different molecular arrangements to predict kinematic viscosities in binary mixtures. McAllister derived model with two forms for the kinematic viscosity of binary liquid mixtures based on absolute rates theory approach of Eyring's viscosity (Eyring, 1936). The McAllister three-body model is shown in (37).

$$
\begin{aligned}
\ln (v)=x_{1}^{3} \cdot \ln ( & \left.v_{1}\right)+3 x_{1}^{2} x_{2} \cdot \ln \left(v_{12}\right)+3 x_{1} x_{2}^{2} \\
& \cdot \ln \left(v_{21}\right)+x_{2}^{3} \cdot \ln \left(v_{2}\right) \\
& -\ln \left(x_{1}+x_{2} \cdot\left[M_{2} / M_{1}\right]\right)+3 x_{1}^{2} x_{2} \\
& \cdot \ln \left(\left[2+M_{2} / M_{1}\right] / 3\right)+3 x_{1} x_{2}^{2} \\
& \cdot \ln \left(\left[1+2 M_{2} / M_{1}\right] / 3\right)+x_{2}^{3} \\
& \cdot \ln \left(M_{2} / M_{1}\right) \\
v_{1}= & \frac{h N}{M_{1}} e^{-\Delta s_{1}^{*} / R} e^{\Delta H_{1}^{*} / R T} \\
v_{12}= & \frac{h N}{M_{12}} e^{-\Delta s_{12}^{*} / R} e^{\Delta H_{12}^{*} / R T}
\end{aligned}
$$




$$
\begin{gathered}
v_{21}=\frac{h N}{M_{21}} e^{-\Delta S_{21}^{*} / R} e^{\Delta H_{21}^{*} / R T} \\
v_{2}=\frac{h N}{M_{2}} e^{-\Delta S_{2}^{*} / R} e^{\Delta H_{2}^{*} / R T}
\end{gathered}
$$

Eyring's viscosity model for Newtonian fluids is given in (8) (Eyring, 1936).

$$
\eta=\frac{h N}{V} \exp \left(\frac{\Delta F^{*}}{R T}\right)
$$

The following (9) and (10) represent the relationship between real and ideal solutions. The excess property $\Delta F^{E *}$ is called the excess free energy of activation for viscous flow.

$$
\begin{gathered}
\ln (\eta V)=\ln (\eta V)_{\text {ideal }}+\frac{\Delta F^{E *}}{R T} \\
\ln (\eta V)=\sum_{i=1}^{n} x_{i} \ln \left(\eta_{i} V_{i}^{o}\right)+\frac{\Delta F^{E *}}{R T} \\
\ln (\eta V)=\sum_{i=1}^{n} x_{i} \ln \left(\eta_{i} V_{i}^{o}\right)+\frac{x_{1} x_{2} W}{R T}
\end{gathered}
$$

A positive $\Delta F^{E *}$ reveals that the real mixture has a greater viscosity than that of an ideal mixture (Heric and Brewer, 1967). Stronger interaction between unlike molecules gives positive values to $\Delta F^{E^{*}}$ and excess viscosity $\eta^{E}$. Further, Meyer et al., (1971) discussed that $\Delta F^{E *}<0$ for the solutions with solute-solute associations. According to Fort and Moore (1966), the $G_{12}$ from Grunberg and Nissan (1949) as shown in (13) provides a better measure for the strength of interactions between components. The interchange energy or the interaction parameter $W / R T$ from the Eyring's viscosity model is proportional to $G_{12}$ and shows the same trend as that of $G_{12}$ (Mukesh et al., 2015).

The ideal viscosity of a liquid mixture is defined in several ways in the literature (Kendall and Monroe, 1917; Bingham, 1922; Cronauer et al., 1965; Martins et al., 2000). Correlations based on Redlich-Kister polynomials to fit the data of $\eta^{E}$ were reported for aqueous MEA solutions (Islam et al., 2004). Nigam and Mahl, (1971) illustrated that the sign of $G_{12}$ along with $\eta^{E}$ from (12) reveals what type of interaction such as strong, weak or dispersion is dominant in the solution.

$$
\begin{gathered}
\eta^{E}=\eta-\left(x_{1} \eta_{1}+x_{2} \eta_{2}\right) \\
\ln \left(\eta_{12}\right)=x_{1} \ln \left(\eta_{1}\right)+x_{2} \ln \left(\eta_{2}\right)+x_{1} x_{2} G_{12}
\end{gathered}
$$

\section{Methodology}

This study focuses on density and viscosity correlations for aqueous MEA and 3A1P mixtures. The study is based on measured density and viscosity data of this and previous works performed in University of SouthEastern Norway (USN) (Idris and Eimer, 2016; Idris et al., 2018). Idris and Eimer, (2016) and Idris et al., (2018) discussed the density and viscosity of aqueous 3A1P solutions under the range of mass fractions $w_{1}$ ( $i=1$ and 2 refer amine and water respectively) within 0 1 and temperatures 293.15-353.15K and 298.15$373.15 \mathrm{~K}$ respectively. The correlation suggested by Aronu et al., (2012) as given in (14) was adopted to correlate aqueous 3A1P density data.

$\rho=\left(k_{1}+\frac{k_{2} x_{2}}{T}\right) \exp \left(\frac{k_{3}}{(T)^{2}}+\frac{k_{4} x_{1}}{T}+k_{5}\left(\frac{x_{1}}{T}\right)^{2}\right)$

The McAllister three-body model is adopted to predict kinematic viscosities of MEA $+\mathrm{H}_{2} \mathrm{O}$ and 3A1P $+\mathrm{H}_{2} \mathrm{O}$ mixtures. The parameters related to the enthalpy and the entropy for viscous flow shown in the (3) to (7) are estimated via regression. The $\Delta F^{E *}$ for $3 \mathrm{~A} 1 \mathrm{P}+\mathrm{H}_{2} \mathrm{O}$ mixtures is calculated using Eying's viscosity model and a Redlich-Kister type polynomial is fitted to represent the viscosity data.

\subsection{Density and Viscosity Measurements}

Densities of aqueous amine solutions were measured using a DMA 4500 density meter from Anton Paar. The measurements of dynamic viscosity performed using a Physica MCR 101 rheometer from Anton Paar. A detailed description of the density meter and rheometer is given in publications based on previous at USN (Han et al., 2012; Idris et al., 2017).

\section{Results and Discussion}

In this section, the accuracy of the data fit of the density and viscosity correlations are determined using Average Absolute Relative Deviation (AARD) and Absolute Maximum Deviation (AMD) as given in (15) and (16).

$$
\begin{aligned}
\operatorname{AARD}(\%) & =\frac{100 \%}{N} \sum_{i=1}^{N}\left|\frac{Y_{i}^{E}-Y_{i}^{C}}{Y_{i}^{E}}\right| \\
A M D & =\operatorname{MAX}\left|Y_{i}^{E}-Y_{i}^{C}\right|
\end{aligned}
$$

\subsection{Density Correlation of 3A1P $+\mathrm{H}_{2} \mathrm{O}$ Mixtures}

The density data of $3 \mathrm{~A} 1 \mathrm{P}+\mathrm{H}_{2} \mathrm{O}$ mixtures were fitted to the correlation described in (14) with $\mathrm{R}^{2}=0.97$. The comparison of measured data with the correlation reveals that the deviation of correlated properties from measured is high at lower temperatures for the different 3A1P concentrations. Nevertheless, the correlation was able to represent data at AARD of $0.2 \%$ and AMD of $6.7 \mathrm{~kg} \cdot \mathrm{m}^{-3}$. The estimated parameters are given in Table 1. Idris and Eimer, (2016) reported several density 
correlation studies based on a Redlich-Kister type polynomial on excess volume, Jouyban-Acree (Jouyban et al., 2005) and Gonzalez-Olmos and Iglesias (Gonzalex-Olmos and Iglesias, 2008). Table 2 summarize absolute average deviations of different correlations fitted for the aqueous 3A1P solutions.

Table 1. Parameters for the Density Correlation for $3 \mathrm{~A} 1 \mathrm{P}+\mathrm{H}_{2} \mathrm{O}$ Mixtures

\begin{tabular}{|c|c|}
\hline Parameter & Value \\
\hline$k_{1}$ & 706 \\
\hline$k_{2}$ & $1.155 \times 10^{5}$ \\
\hline$k_{3}$ & -7633 \\
\hline$k_{4}$ & 112.1 \\
\hline$k_{5}$ & 3602 \\
\hline
\end{tabular}

Table 2. Absolute Average Deviation Measured and Correlated Densities for 3A1P $+\mathrm{H}_{2} \mathrm{O}$ Mixtures

\begin{tabular}{|c|c|}
\hline Correlation & $\begin{array}{c}\text { Absolute average } \\
\text { deviation }\left(\mathrm{kg} \cdot \mathrm{m}^{-3}\right)\end{array}$ \\
\hline Aronu (this work) & 1.9 \\
\hline Redlich-Kister & 0.5 \\
\hline Jouyban-Acree & 2 \\
\hline $\begin{array}{c}\text { Gonzalez-Olmos and } \\
\text { Iglesias }\end{array}$ & 0.7 \\
\hline
\end{tabular}

The correlation for excess volume was based on a Redlich-Kister polynomial with 39 parameters for the considered temperature range. Three parameters were estimated at each temperature level by fitting the correlation into the calculated excess volume using measured densities. The Jouyban-Acree correlation used only three parameters and absolute average deviation is similar to this study. A semiempirical model proposed by Gonzalez-Olmos and Iglesias with 12 parameters was used to correlate densities over the range of 3A1P mole fractions and temperatures.

The considered correlations in this study and the literature for the density of 3A1P have acceptable accuracy. The advantage of correlations proposed by Aronu, Jouyban-Acree and Gonzalez-Olmos and Iglesias is that they can be easily used in the mathematical modelling and simulations of a pilot or large-scale absorption processes. The models including parameters can be implemented in simulation programs like Aspen Plus or in programming tool like MATLAB.

\subsection{Viscosity Correlation of $\mathrm{MEA}+\mathrm{H}_{2} \mathrm{O}$ and 3A1P $+\mathrm{H}_{2} \mathrm{O}$ Mixtures}

The calculated kinematic viscosity of MEA $+\mathrm{H}_{2} \mathrm{O}$ and $3 \mathrm{~A} 1 \mathrm{P}+\mathrm{H}_{2} \mathrm{O}$ mixtures from dynamic viscosity and density were correlated using McAllister three-body model. The estimated parameters that are related to the activation energies of the mixtures are given in Table 3. These parameters were assumed constant over the considered temperature range.
Table 3. Parameter in McAllister Three-Body Model

\begin{tabular}{|l|l|l|}
\hline Mixture & $\Delta H^{*} / \mathrm{kJ} \cdot \mathrm{mol}^{-1}$ & $\Delta S^{*} / J \cdot \mathrm{mol}^{-1} \mathrm{~K}^{-1}$ \\
\hline MEA $+\mathrm{H}_{2} \mathrm{O}$ & $\Delta H_{1}^{*}=28.068$ & $\Delta S_{1}^{*}=28.39$ \\
\hline & $\Delta H_{12}^{*}=31.668$ & $\Delta S_{12}^{*}=15.32$ \\
\hline & $\Delta H_{21}^{*}=30.271$ & $\Delta S_{21}^{*}=42.45$ \\
\hline & $\Delta H_{2}^{*}=13.677$ & $\Delta S_{2}^{*}=36.45$ \\
\hline & & \\
\hline $3 \mathrm{~A} 1 \mathrm{P}+\mathrm{H}_{2} \mathrm{O}$ & $\Delta H_{1}^{*}=33.073$ & $\Delta S_{1}^{*}=39.03$ \\
\hline & $\Delta H_{12}^{*}=31.410$ & $\Delta S_{12}^{*}=11.27$ \\
\hline & $\Delta H_{21}^{*}=43.316$ & $\Delta S_{21}^{*}=40.30$ \\
\hline & $\Delta H_{2}^{*}=12.429$ & $\Delta S_{2}^{*}=67.08$ \\
\hline
\end{tabular}

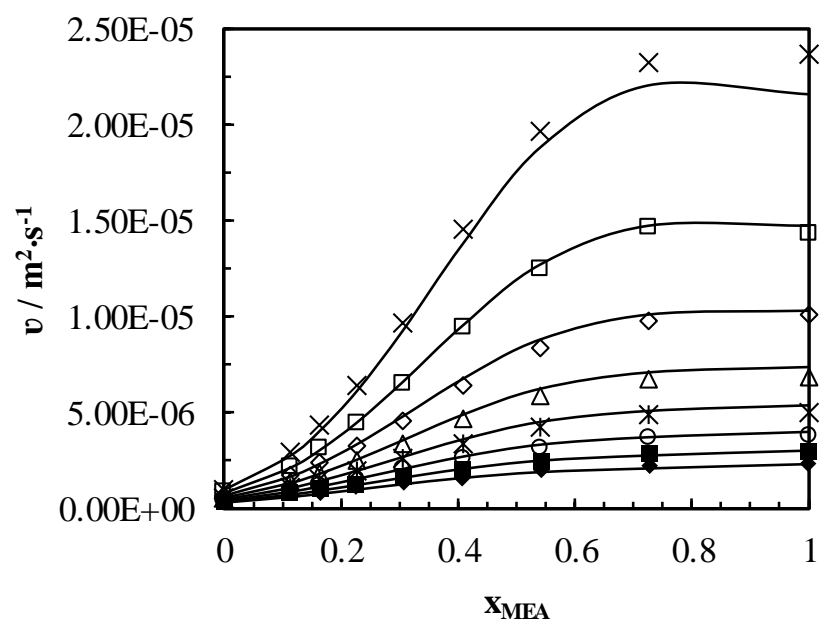

Figure 1. Kinematic viscosity of $\mathrm{MEA}+\mathrm{H}_{2} \mathrm{O}$ mixtures at

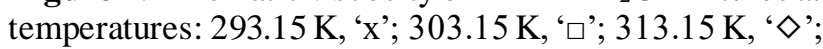
$323.15 \mathrm{~K}, \triangle^{\prime}$ '; $333.15 \mathrm{~K}$, ‘ж’; $343.15 \mathrm{~K}$, 'о’; $353.15 \mathrm{~K}$, ' $\boldsymbol{~}$ '; $363.15 \mathrm{~K}$, ' $\diamond$ '. The solid lines represent the McAllister model.

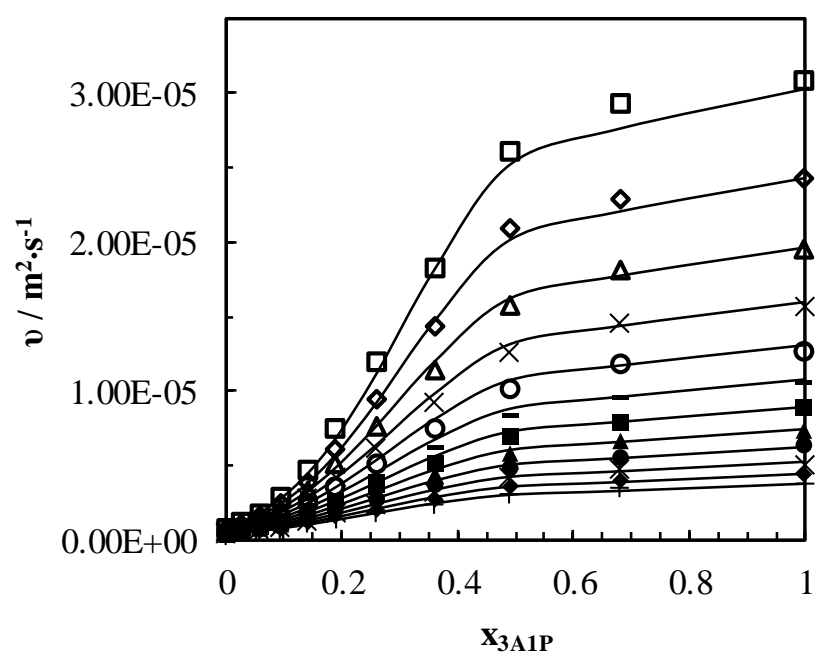

Figure 2. Kinematic viscosity of $3 \mathrm{~A} 1 \mathrm{P}+\mathrm{H}_{2} \mathrm{O}$ mixtures at

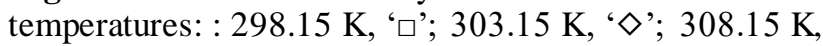

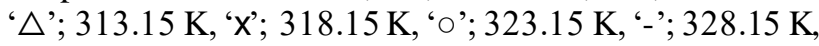

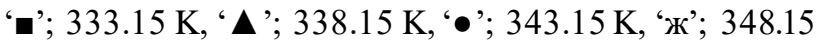
$\mathrm{K}$, ' '; $353.15 \mathrm{~K}$, '十'. The solid lines represent the McAllister model. 
The McAllister three-body model was able to represent the kinematic viscosity of MEA $+\mathrm{H}_{2} \mathrm{O}$ and $3 \mathrm{~A} 1 \mathrm{P}+\mathrm{H}_{2} \mathrm{O}$ with acceptable accuracy. Table 2 provides an overview of the accuracy based on AARD and AMD of the mixtures. For MEA $+\mathrm{H}_{2} \mathrm{O}$, model deviates from the data at high MEA concentrations and low temperatures as shown in Figure 1. The highest deviations were observed at $\mathrm{X}_{\mathrm{MEA}}=0.726\left(w_{1}=0.9\right)$ and $\mathrm{X}_{\mathrm{MEA}}=1\left(w_{1}=1\right)$ at $293.15 \mathrm{~K}$. The average absolute deviation of the correlated data is $1.68 \times 10^{-7}$ $\mathrm{m}^{2} \cdot \mathrm{s}^{-1}$. For $3 \mathrm{~A} 1 \mathrm{P}+\mathrm{H}_{2} \mathrm{O}$ mixtures, the deviation is high at higher temperatures for the mixtures up to $\mathrm{X}_{3 \mathrm{~A} 1 \mathrm{P}} \leq$ 0.057 and it becomes high at lower temperatures for the mixtures with $\mathrm{X}_{3 \mathrm{~A} 1 \mathrm{P}}>0.057$ as illustrated in Figure 2. The average absolute deviation of the correlated data is $1.62 \times 10^{-7} \mathrm{~m}^{2} \cdot \mathrm{s}^{-1}$.

Table 4. Calculated AARD and AMD of the McAllister Three-Body Model for the MEA $+\mathrm{H}_{2} \mathrm{O}$ and 3A1P + $\mathrm{H}_{2} \mathrm{O}$

\begin{tabular}{|c|c|c|}
\hline Mixture & AARD \% & $A M D m^{2} \cdot \mathrm{s}^{-1}$ \\
\hline $\mathrm{MEA}+\mathrm{H}_{2} \mathrm{O}$ & 3.17 & $1.42 \times 10^{-6}$ \\
\hline $3 \mathrm{~A} 1 \mathrm{P}+\mathrm{H}_{2} \mathrm{O}$ & 3.66 & $1.71 \times 10^{-6}$ \\
\hline
\end{tabular}

The $\Delta F^{E *}$ was determined using measured density and viscosity for aqueous 3A1P mixtures at different temperatures. A Redlich-Kister type polynomial was fitted for the $\Delta F^{E *}$ and viscosity of aqueous 3A1P mixtures were obtained accordingly. This correlation used molar volumes of mixtures to determine the viscosity. For this study, the calculated molar volumes from density data were used and it is possible to use the density correlation that was discussed in this study or correlations in the literature to acquire molar volumes for the situations when measured data are not available. The correlation was able to fit the viscosity data with AARD of $2.7 \%$ and AMD of $1.1 \mathrm{mPa} \cdot \mathrm{s}$ at $w_{1}=0.8$ and temperature of $303.15 \mathrm{~K}$. These deviations are acceptable for engineering calculations.

Figure 3 shows the comparison between measured and correlated viscosities for $3 \mathrm{~A} 1 \mathrm{P}+\mathrm{H}_{2} \mathrm{O}$ mixtures. The $\Delta F^{E *}$ is positive for the considered range of 3A1P concentrations and temperatures. According to Heric and Brewer, (1967), if $\Delta F^{E *}>0$, the viscosity of a real mixture is greater than that of an ideal mixture. This emphasizes strong intermolecular attractions in the solution. As reported by Idris et al., (2018), $\eta^{E}<0$ for the water rich region indicates weak intermolecular attractions. The presence of strong intermolecular attractions is determined as $\eta^{E}>0$ for amine rich region. The interaction parameter $G_{12}$ proposed by Grunberg and Nissan, (1949) for binary mixtures behaves similar to $\Delta F^{E *}$, that is positive for considered 3A1P concentrations. Nigam and Mahl, (1971) show that for the weak intermolecular attractions $G_{12}>0$ and $\eta^{E}<0$.

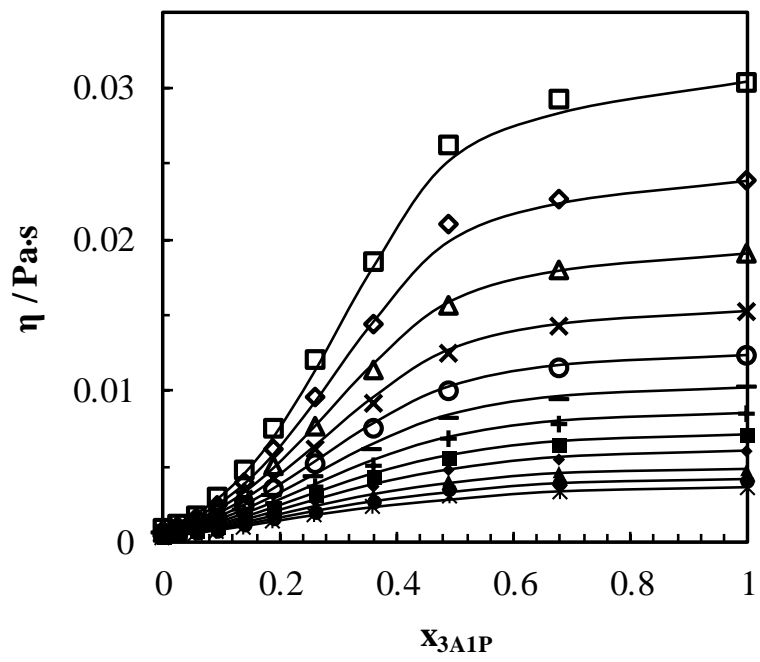

Figure 3. Dynamic viscosity of $3 \mathrm{~A} 1 \mathrm{P}+\mathrm{H}_{2} \mathrm{O}$ mixtures at

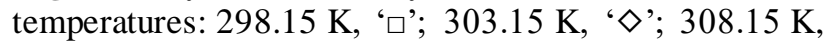

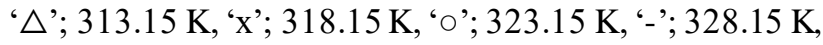

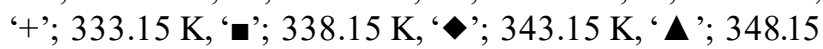
$\mathrm{K}$, '•’; $353.15 \mathrm{~K}$, ' $¥$ '. The solid lines represent the correlation.

\subsection{Recommended Correlations for Simulations}

Mathematical modelling of the absorption process is based on material and energy balance of the gas/liquid interface. The composition and the temperature of the solvent vary continuously through the column for both steady state and dynamic conditions. Physical property correlations as a continuous function of composition and temperature can be easily implemented in a programming tool like MATLAB for both steady state and dynamic simulations.

In this study, the parameters of the Aronu's density correlation were evaluated in such a way that concentration and temperatures can be considered as continuous independent variables. The other advantages of this correlation are it is simple and accuracy is acceptable. The McAllister three-body model for kinematic viscosity can be easily converted into code with all the parameters as discussed in this study. The proposed Redlich-Kister polynomial for the Eyring's viscosity model is a continuous function of concentration and temperature. Accordingly, viscosity variations related to the changes in compositions and temperatures in the column can be observed and correlation can be used in other mass and heat transfer correlations.

\section{Conclusion}

This study discusses the density and viscosity correlations for the mixtures of MEA $+\mathrm{H}_{2} \mathrm{O}$ and 3A1P $+\mathrm{H}_{2} \mathrm{O}$. The considered correlations can be used in mathematical models such as continuity, momentum 
and energy equations to perform simulations in e.g. amine based absorption and desorption processes.

The correlations for measured density and viscosity data of aqueous mixtures of MEA and 3A1P were discussed. Density data of aqueous 3A1P was correlated by the empirical correlation proposed by Aronu and was able to represent density data with AARD of $0.2 \%$ that is satisfactory in engineering calculations.

The McAllister three-body model was adopted to fit kinematic viscosity data for aqueous MEA and aqueous 3A1P mixtures. The energy parameters in the model were evaluated through a regression. The three-body model can correlate kinematic viscosities for considered mixtures with acceptable accuracy having AARD of 3\% and $4 \%$ for aqueous MEA and aqueous 3A1P mixtures respectively.

The viscosity correlation based on a Redlich - Kister type polynomial for the excess free energy of activation for viscous flow using the Eyring's viscosity model was developed to correlate viscosity data of $3 \mathrm{~A} 1 \mathrm{P}+\mathrm{H}_{2} \mathrm{O}$ mixtures. The viscosity data were in good agreement with correlated viscosities with AARD of $2.7 \%$.

\section{Nomenclature}

\begin{tabular}{|c|c|}
\hline$\Delta F^{*}$ & $\begin{array}{l}\text { Free energy of activation for viscous flow } \\
\left(\mathrm{J} \cdot \mathrm{mol}^{-1}\right)\end{array}$ \\
\hline$\Delta F^{E *}$ & $\begin{array}{l}\text { Excess free energy of activation for viscous } \\
\text { flow }\left(\mathrm{J} \cdot \mathrm{mol}^{-1}\right)\end{array}$ \\
\hline$G_{12}$ & Characteristic constant \\
\hline$h$ & Planck's constant (J.s) \\
\hline$\Delta H^{*}$ & $\begin{array}{l}\text { Enthalpy of activation for viscous flow } \\
\left(\mathrm{J} \cdot \mathrm{mol}^{-1}\right)\end{array}$ \\
\hline$k$ & Parameters of Eq (14) \\
\hline$M$ & Molecular weight $\left(\mathrm{kg} \cdot \mathrm{mol}^{-1}\right)$ \\
\hline$N$ & Avogadro's number \\
\hline$R$ & Gas constant $\left(\mathrm{J} \cdot \mathrm{mol}^{-1} \cdot \mathrm{K}^{-1}\right)$ \\
\hline$\Delta S^{*}$ & $\begin{array}{l}\text { Entropy of activation for viscous flow } \\
\left(\mathrm{J} \cdot \mathrm{mol}^{-1} \cdot \mathrm{K}^{-1}\right)\end{array}$ \\
\hline$T$ & Temperature $(\mathrm{K})$ \\
\hline$V$ & Molar volume of mixture $\left(\mathrm{m}^{3} \cdot \mathrm{mol}^{-1}\right)$ \\
\hline$V^{E}$ & Excess molar volume $\left(\mathrm{m}^{3} \cdot \mathrm{mol}^{-1}\right)$ \\
\hline$V_{i}^{o}$ & Molar volume of pure liquids $\left(\mathrm{m}^{3} \cdot \mathrm{mol}^{-1}\right)$ \\
\hline$W$ & Interchange energy $\left(\mathrm{J} \cdot \mathrm{mol}^{-1}\right)$ \\
\hline$x$ & Mole fraction \\
\hline$Y_{i}^{E}$ & Measured property \\
\hline$Y_{i}^{C}$ & Calculated property \\
\hline
\end{tabular}

\section{Greek letters}

$\begin{array}{ll}\eta & \text { Dynamic viscosity }(\mathrm{Pa} \cdot \mathrm{s}) \\ v & \text { Kinematic viscosity }\left(\mathrm{m}^{2} \cdot \mathrm{s}^{-1}\right) \\ \rho & \text { Density }\left(\mathrm{kg} \cdot \mathrm{m}^{-3}\right)\end{array}$

\section{References}

T. G. Amundsen, L. E. Øi, and D. A. Eimer. Density and viscosity of monoethanolamine + water + carbon dioxide from (25 to 80) ${ }^{\circ}$ C. J. Chem. Eng. Data, 54: 3096-3100, 2009.

U. E. Aronu, A. Hartono, and H. F. Svendsen. Density, viscosity, and $\mathrm{N}_{2} \mathrm{O}$ solubility of aqueous amino acid salt and amine amino acid salt solutions. J. Chem. Thermodynamics, 45: 90-99, 2012.

E. C. Bingham. Fluidity and plasticity. McGraw-Hill, New York, 1922.

D. C. Cronauer, R. R. Rothfus, and R. I. Kernmore. Viscosity and density of the ternary liquid system acetone-benzeneethylene dichloride. J. Chem. Eng. Data, 10: 131-133, 1965.

D. A. Eimer. Gas Treating: Absorption Theory and Practice. John Wiley \& Sons Ltd, 2014.

H. Eyring. Viscosity, Plasticity, and Diffusion as example of absolute reaction rates. Journal of chemical physics, 4: 283291, 1936.

R. J. Fort and W. R. Moore. Viscosities of binary liquid mixtures. Transactions of the faraday society, 62: 11121119, 1966

R. Gonzalez-Olmos and M. Iglesias. Influence of temperature on thermodynamics of ethers + xylenes. Fluid Phase Equilibria, 267(2):133-139, 2008. doi:10.1016/j.fluid.2008. 03.004 .

L. Grunberg and A. H. Nissan. Mixture Law for Viscosity. Nature, 164(4175): 799-800, 1949. doi:10.1038/164799b0.

J. Han, J. Jin, D. A. Eimer, and M. C. Melaaen. Density of water (1) + Monoethanolamine (2) $+\mathrm{CO}_{2}$ (3) from (298.15 to 413.15) $\mathrm{K}$ and surface tension of water (1) + Monoethanolamine (2) from (303.15 to 333.15) K. J. Chem. Eng. Data, 57: 1095-1103, 2012.

A. Hartono, M. O. Mba, and H. F. Svendsen. Physical properties of partially $\mathrm{CO}_{2}$ loaded aqueous monoethanolamine (MEA). J. Chem. Eng. Data, 59: 18081816, 2014.

E. L. Heric and J. G. Brewer. Viscosity of some binary liquid nonelectrolyte mixtures. J. Chem. Eng. Data, 12(04): 574583, 1967.

Z. Idris and D. A. Eimer. Density measurements of unloaded and $\mathrm{CO}_{2}$ loaded 3-Amino-1-propanol solutions at temperatures (293.15 to 353.15) K. J. Chem. Eng. Data, 61(1): 173-181, 2016.

Z. Idris, N. B. Kummamuru, and D. A. Eimer. Viscosity measurement of unloaded and $\mathrm{CO}_{2}$-loaded aqueous monoethanolamine at higher concentrations. Journal of Molecular Liquids, 243: 638-645, 2017.

Z. Idris, N. B. Kummamuru, and D. A. Eimer. Viscosity measurement and correlation of unloaded and $\mathrm{CO}_{2}$ loaded 3-Amino-1-propanol solution. J. Chem. Eng. Data, 63: 1454-1459, 2018.

M. N. Islam, M. M. Islam, and M. N. Yeasmin. Viscosity of aqueous solution of 2-methoxyethanol, 2-ethoxyethanol, and ethanolamine. J. Chem. Thermodynamics, 36:889-893, 2004.

A. Jouyban, A. Fathi-Azarbayjani, M. Khoubnasabjafari, and W. E. Acree. Mathematical representation of the density of 
liquid mixtures at various temperatures using JouybanAcree model. Indian Journal of Chemistry, 44A: 15531560, 2005.

J. Kendall and P. Monroe. The viscosity of liquids. II. The viscosity-composition curve for ideal liquid mixtures. $J$. Am. Chem. Soc, 39: 1787-1802, 1917.

R. J. Martins, M. J. D. M. Cardoso, and O. E. Barcia. Excess Gibbs free energy model for calculating the viscosity of binary liquid mixtures. Ind. Eng. Chem. Res, 39: 849-854, 2000.

R. A. McAllister. The viscosity of liquid mixtures. A.I.Ch.E. Journal, 6: 427-431, 1960.

R. Meyer, M. Meyer, J. Metzger, and A. Peneloux. Thermodynamic and physicochemical properties of binary solvent. Journal de Chimie Physique et de Physico-Chimie Biologique, 68: 406-412, 1971.

B. Mukesh, M. G. Sankar, M. C. Shekar, and T. Srikanth. Effect of placement of hydroxyl groups in isomeric butanol on the behavior of thermophysical and spectroscopic properties of 2-Methoxyaniline. Journal of Solution Chemistry, 44(12): 2267-2296, 2015. doi:10.1007/s10953015-0406-1.

R. K. Nigam and B. S. Mahl. Molecular interaction in binary liquid mixtures of dimethylsulfoxide with chlroethanes \& chlroethenes. Indian Journal of Chemistry, 9:1255-1258, 1971.

O. Redlich and A. T. Kister. Algebraic representation of thermodynamic properties and the classification of solutions. Industrial and engineering chemistry, 40(2): 345348, 1948.

G. T. Rochelle. Amine Scrubbing for $\mathrm{CO}_{2}$ Capture. Science, 325(5948): 1652-1654, 2009. 